\title{
Structural Investigation on Cooling Design influences in Rene-77 made Gas Turbine Guide Vanes
}

\author{
Dr.R.Saravanan*, G.Vinod Reddy \\ *Principal \& Professor, Department of Mechanical Engineering, Elenki Institute of Engineering and \\ Technology, Hyderabad, TS, India. E.mail: dr.rsaravanan@yahoo.com, ph. 9884522445. \\ Assistant Professor, Department of Mechanical Engineering, Ellenki College of Engineering and Technology, \\ Hyderabad, TS, India. E.mail: vinod.reddy315@gmail.com ph.888689700.,
}

\begin{abstract}
Even though high temperature materials are preferred for gas turbine blades and guide vanes, appropriate design of its cooling is imperative. Selection of cooling and its design is very intricate task. With extreme care, knowledge and sophisticated facilities required to perform them. This research investigates the cooling designs on gas turbine guide vane made-up of Rene -77. Both existing impingement cooling designs as well as an improved showerhead cooling design are investigated. The structural design and finite element analysis performed in Pro/E. The result shows that the improved design out performs.
\end{abstract}

Index Terms-Rane-77, gas turbine, guide vane, cooling design, structural analysis

\section{INTRODUCTION}

Application of gas turbine is vital and their design must ensure the safety in operation, less operating cost, reliable in operation with greater efficiency[1]. Increases of temperature difference between the inlet and exit of gas turbine to improve powder density as well as thermal efficiency is a nowadays trend[2,3]. Gas turbine has stationary and moving blades and that are exposed to the gas temperature approximately $1500^{\circ} \mathrm{C}$. The high operating temperature and small variation between their melting and operating temperature spoil the airfoils and blade life span[4]. The compressed air (at $650^{\circ} \mathrm{C}$ ) used for maintaining their temperature around $1000^{\circ} \mathrm{C}$. The reliable operation can be ensured by perfect cooling by preventing premature failure of blades and vanes[5]. The design of complicated and challenging task because it involves complex interaction, numerical analysis, developing turbulent layer, forming streamlines etc., over curved surfaces[6]. [7] studied about the performance of turbulent slot jet cooling on concave plates. The authors varied the surface curvatures and finally reported that the outstanding cooling performance achieved at $\mathrm{R} / \mathrm{L}=1.3$, which is a dimensionless value of the curvature of impinging surfaces. In later [8] investigated further and developed $\mathrm{k}-\varepsilon$ turbulence model. $[9,10]$ studied such slot impingement on circular dish. [11] reported that among various turbulence models, the $\mathrm{k}-\mathcal{E}$ models produce perfect results over the impingement surface. [12] experimentally and numerically investigated showerhead cooled turbine guide vanes and concluded that $18 \%$ and $44 \%$ of temperature peaks are reduced at the leading edge. [13] optimized the size and number of passages in the gas turbine guide vanes. The authors analyzed circular holes varies in number, size and locations. [14] conducted nnumerical simulation to predict swirl cooling on the circular passage in two rectangular sections of internal leading edge of the blade. [15] studied by Numerical investigation on the effect of rim seal and end wall flows of the turbine and its airfoil design parameters. ANSYS is generally employed for design Mechanical Machines, investigates alternate materials and their compatibility for the applications. For example Saravanan et al [16] designed Two-Wheeled Inverted Pendulum for the Material Handling. The authors used CATIA for 3D modelling of structural components like the handle, motor bracket,wheel Boss, support stem of handlebar, loading platform, base plate, Flange, support bracket, etc and assembled them and analyzed by means of Finite Element Analysis in ANSYS work bench. Saravanan et al [17] investigated alternate material for the drive shaft. The authors considered composite materials like Eglass/epoxy proposed and Kevlar29/epoxy composites along with conventional steel of grade SM45. The ANSYS R14.5 is employed for FEA and found Kevlar29/epoxy composites reduced weight by $81.05 \%$, $0.22 \%$ reduction of traditional stress and $57.1 \%$ increased buckling capacity than conventional steel.

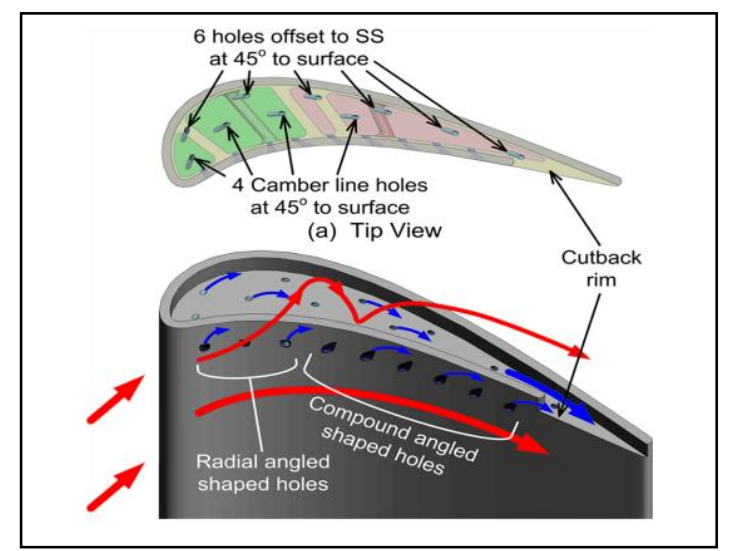

Figure 1. Impingement cooling type Guide vane

But this research focuses on design for cooling on guide vanes. The guide vanes are a number of fixed blades that arranged between two parallel covers and normal to the turbine shaft. By adjusting them the flow rate can be 
varied. The impingement type cooling is widely used on the leading edge of the airfoils and in the mid-chord of the vane where the heat loads are extremely high. The Figure 2 exhibits a jet impingement that located throughout the cross-section of an inlet guide vane. According to their findings film cooling performance can be improved by adding showerhead with fan-shaped holes. An optimal cooling design depends on many factors such as state of approaching flow, blowing ratio, hole shape, the number of cooling rows and cooling type. This investigation is focused with showerhead cooling in the place of impingement type cooling.

\section{MATERIALS AND METHODS}

\section{RENE 77}

Rane 77 is a nickel based super alloy, has wide range of high temperature $\left(600-1200{ }^{\circ} \mathrm{C}\right)$ applications like gas turine, petroleum, ship, aviation, space flight etc. Rane 77 can withstand long term stress even at elevated temperatures and also posses good oxidation resistance, good corrosion resistance, good strength, impact toughness, creep properties, and good fracture toughness etc. it exhibits good stability and reliability in internal (chemical compositions) as well as external (physical and mechanical properties)[18]. The chemical compositions are furnished in Table 1 and physical and Mechanical properties are listed in Table 2.

Table 1. Chemical Composition of Rane 77

\begin{tabular}{|c|l|}
\hline $\begin{array}{c}\text { Chemical } \\
\text { Composition }\end{array}$ & \multicolumn{1}{|c|}{ mass $\%$} \\
\hline $\mathrm{C}$ & $0.05-0.09$ \\
\hline $\mathrm{Al}$ & $4.0-4.6$ \\
\hline $\mathrm{Co}$ & $14.25-15.75$ \\
\hline $\mathrm{Ti}$ & $3.0-3.7$ \\
\hline $\mathrm{Mo}$ & $3.9-4.5$ \\
\hline $\mathrm{Cr}$ & $14.0-15.25$ \\
\hline $\mathrm{Ni}$ & 57 \\
\hline $\mathrm{Ta}$ & 0.05 \\
\hline $\mathrm{B}$ & 0.015 \\
\hline $\mathrm{Zr}$ & 0.01 \\
\hline $\mathrm{Fe}$ & 0.08 \\
\hline $\mathrm{S}$ & 0.001 \\
\hline $\mathrm{Si}$ & 0.017 \\
\hline
\end{tabular}

Table 2. Physical and Mechanical Properties of Rane 77

\begin{tabular}{|l|l|}
\hline Property Description & Property Value \\
\hline Tensile Strength & $650-880 \mathrm{~N} / \mathrm{mm}^{2}$ or \\
& $\mathrm{MPa}$ \\
\hline Yield Strength & $350-550 \mathrm{~N} / \mathrm{mm}^{2}$ or \\
& $\mathrm{MPa}$ \\
\hline Young's Modulus & $200000-200000$ \\
& $\mathrm{MPa}$ \\
\hline Poisson's ratio & $0.27-0.30$ \\
\hline Elongation & $8-25 \%$ \\
\hline Melting Range & $1450^{\circ} \mathrm{C}-1510^{\circ} \mathrm{C}$ \\
\hline Density & $7800 \times 10^{-6} \mathrm{~kg} / \mathrm{mm}^{3}$ \\
\hline Mean coefficient of linear thermal & $17.510^{-6} /{ }^{\circ} \mathrm{C}$ \\
\hline
\end{tabular}

\begin{tabular}{|l|l|}
\hline expansion & \\
\hline Fatigue & $275 \mathrm{MPa}$ \\
\hline Elastic Modulus & $190-210 \mathrm{GPa}$ \\
\hline
\end{tabular}

\section{STRUCTURAL ANALYSIS}

The conventional design is considered for investigation along with improved design and their dimensional particulars are illustrated with Pro/ENGINEER (Pro/E) sketches in Figure1 and Figure 2. The modeling task performed with Pro/ENGINEER (Pro/E).

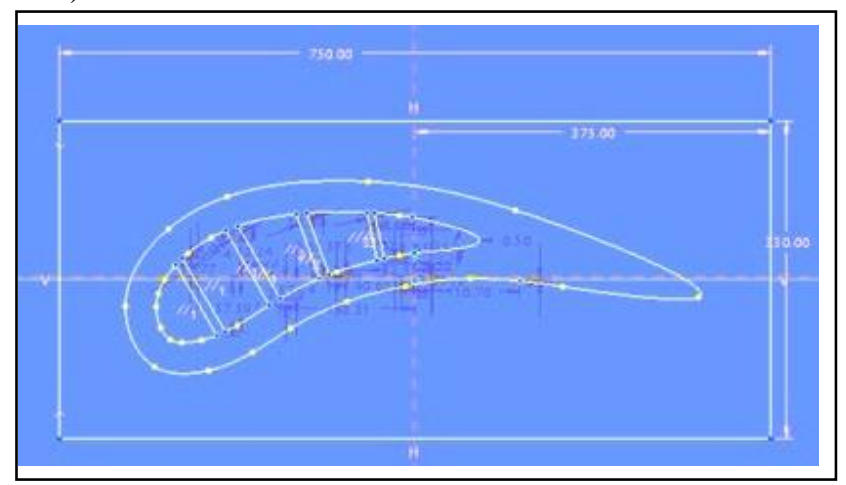

Figure 1 Profile and Dimensions of Impingement cooling type

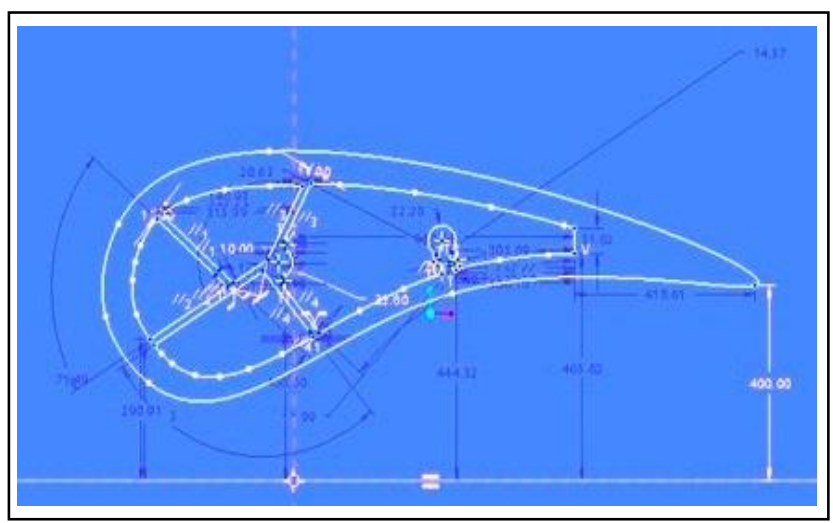

Figure 2 Profile and Dimensions of Showerhead cooling type

\section{FINITE ELEMENTAL ANALYSIS}

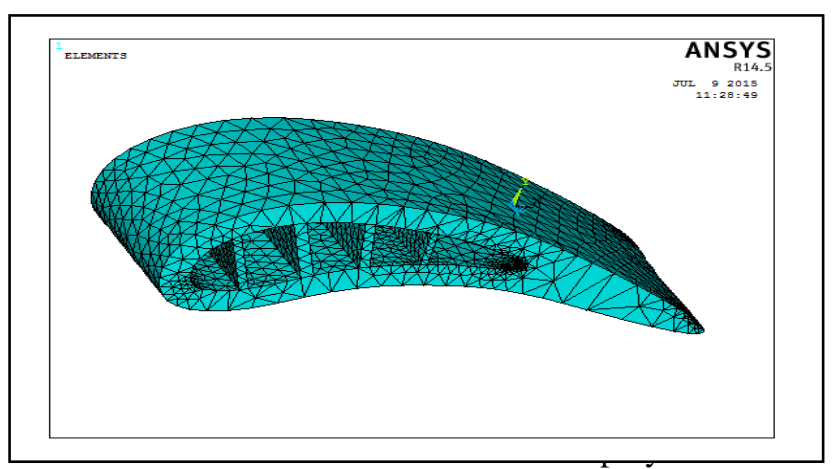

analysis part. The mechanical and physical properties

Figure 3 Meshed model of Impingement cooling type 
were used in the model with 186 nodes. The meshed models of conventional and improved designs are shown

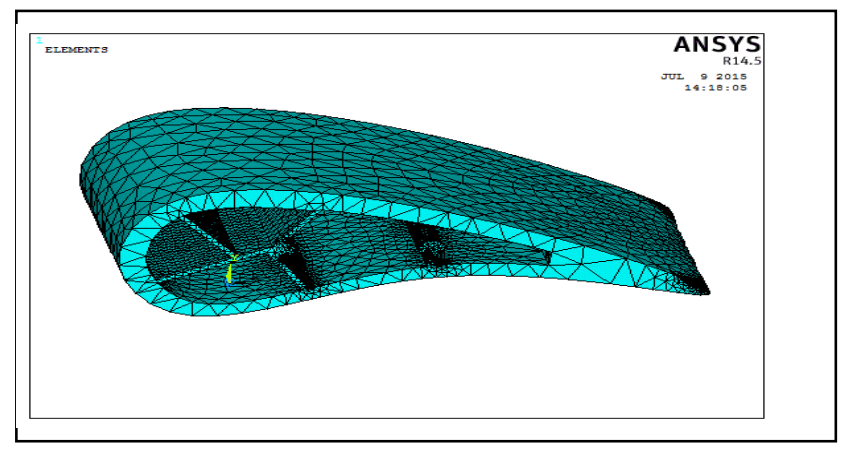

Figure 4 Meshed model of Showerhead cooling type

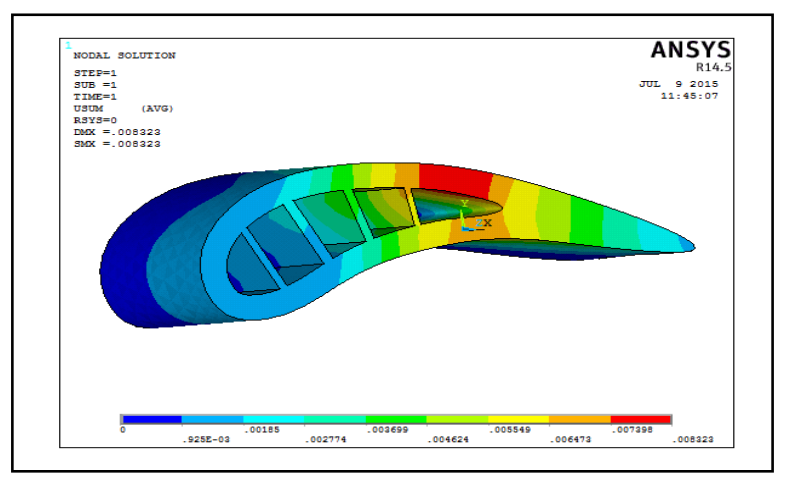

Figure 5 Displacement analyses for Impingement cooling type

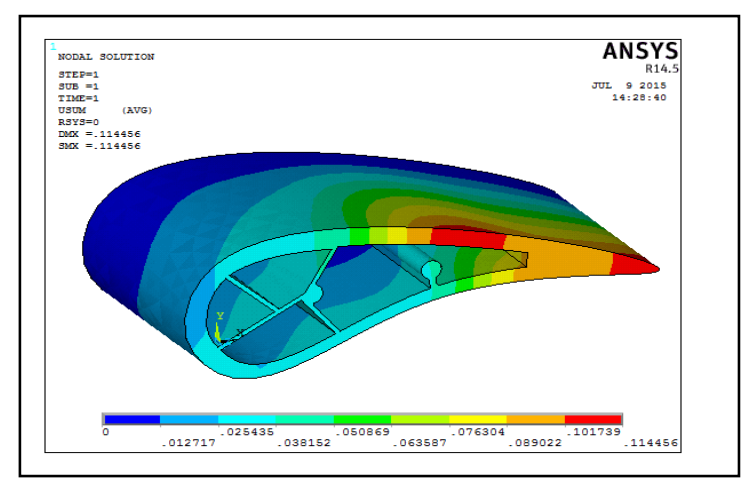

Figure 6 Displacement analysis for Improved Design

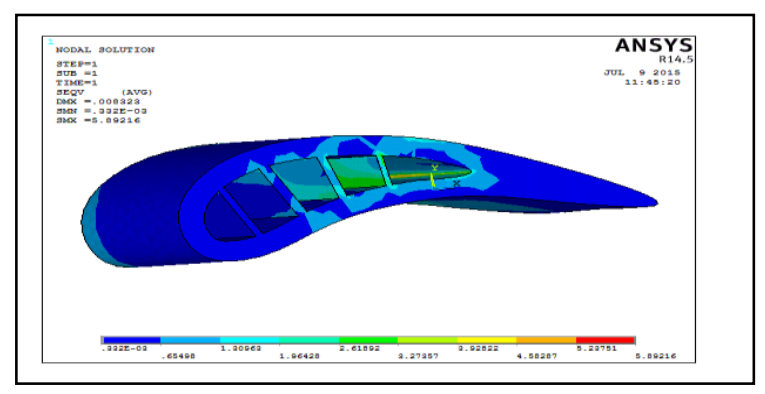

Figure 7 Stress analysis for Conventional Design

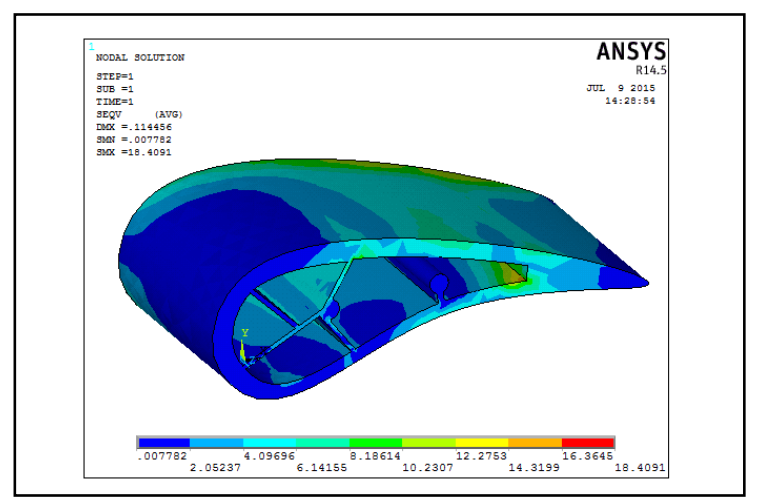

Figure 8 Stress analysis for Improved Design

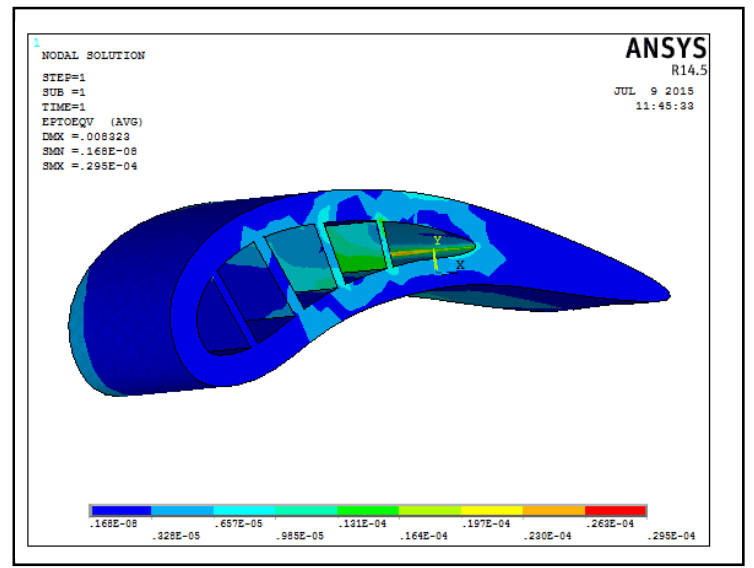

Figure 9 Strain analysis for conventional Design

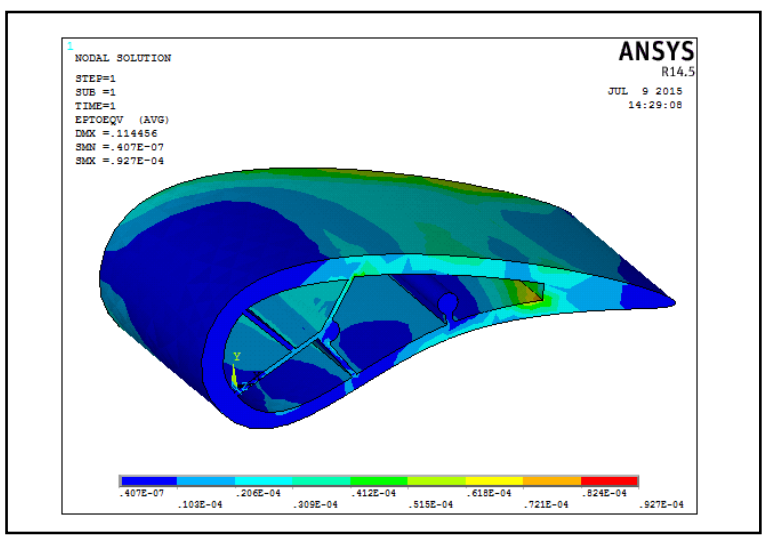

Figure 10 Strain analysis for Improved Design

in Figure 3 and Figure 4 respectively. The load and displacement analysis results are displayed in Figure 5 and Figure 6 for conventional and improved designs respectively. The stress analysis (Figure 7 and Figure 8 for conventional and improved designs respectively) and strain analysis (Figure 9 and Figure 10) for conventional and improved designs respectively) were also investigated. 


\section{III.RESULTS AND DISCUSSION}

The displacement analysis resulted that $0.106133 \mathrm{~mm}$ higher than the conventional design. This means that the new design offers additional flexibility when load applied. Hence the lesser chance to break. In case of stress analysis 12.5169 MPa higher than conventional guide vane, which results that improved cooling design gives additional strength to withstand. The strain is $6.32 \mathrm{E}-05$ more than conventional vane. This implied that the load bearing capacity increased significantly. The results are tabulated in Table 3.The results are compared for the displacement analysis results in Figure 11, stress analysis results in Figure 12 and strain analysis results in Figure 13.

Table 3. Results of Structural Analysis

\begin{tabular}{|l|l|l|}
\hline \multicolumn{1}{|c|}{ Results } & \multicolumn{1}{|c|}{$\begin{array}{c}\text { Impingement } \\
\text { Cooling Design }\end{array}$} & $\begin{array}{c}\text { Showerhead } \\
\text { Cooling } \\
\text { Design }\end{array}$ \\
\hline $\begin{array}{l}\text { Displacement } \\
(\mathrm{mm})\end{array}$ & 0.008323 & 0.114456 \\
\hline Stress $\left(\mathrm{N} / \mathrm{mm}^{2}\right)$ & 5.89216 & 18.4091 \\
\hline Strain & $2.95 \mathrm{E}-05$ & $9.27 \mathrm{E}-05$ \\
\hline
\end{tabular}

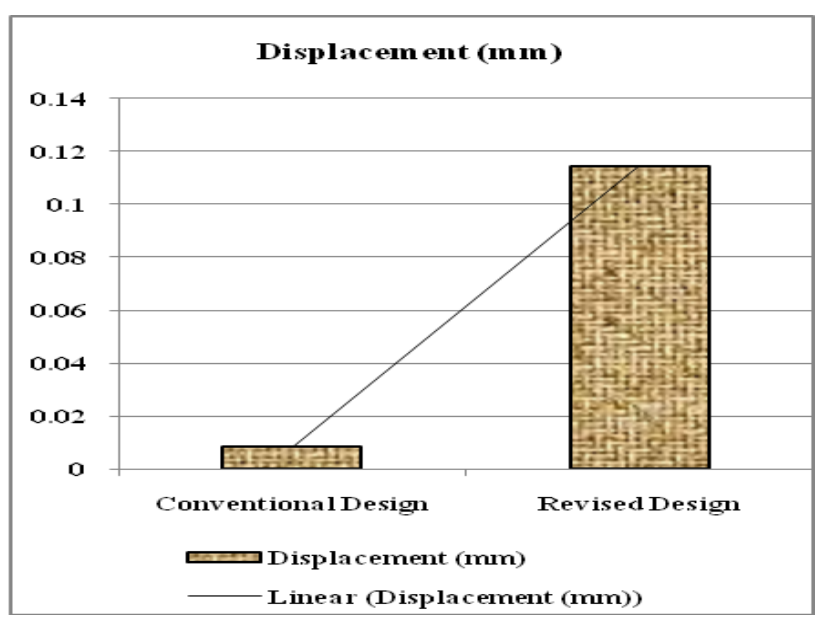

Figure 11 Displacement Vs Cooling Design

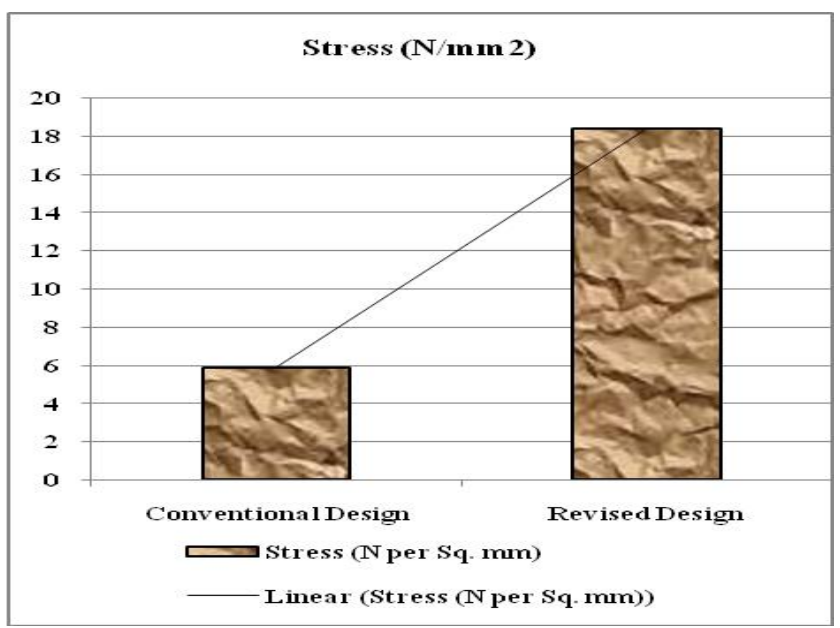

Figure 12 Stress Vs Cooling Design

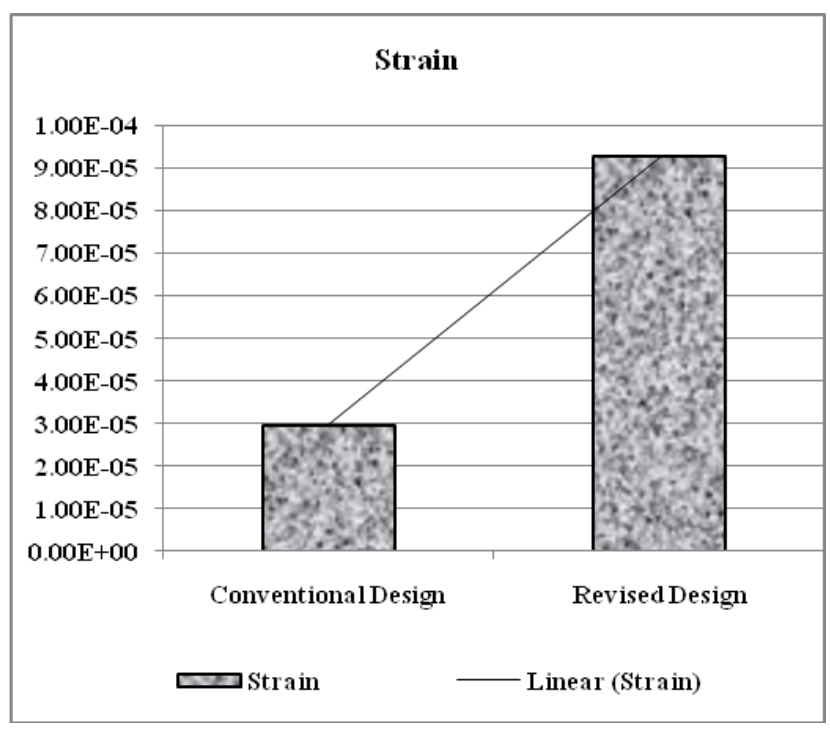

Figure 13 Strain Vs Cooling Design

\section{CONCULUSION}

The cooling is imperative for gas turbine blades. The cooling design influences on its structural stability. In this research, the conventional impingement cooling design as well as newly designed showerhead cooling design on Rane77 made gas turbine blades are considered for investigating structural stability. The results reveal that the newly designed showerhead cooling design on Rane77 made gas turbine blade has good structural stability than conventional design. Present investigation ensures the structural stability and the further investigation could be made to ensure the cooling performances.

\section{REFERENCES}

[1] I.G. Amos, T. Jablonowski, E. Rossi, D. Vogt, P. Boncinelli, "Design and off-design optimisation of highly loaded industrial gas turbine stages", Applied Thermal Engineering, 24, 1735-1744, 2004.

[2] JC Han, "Recent studies in turbine blade cooling", International Journal of Rotating Machanics, 10, 443457, 2004.

[3] JC Han, M. Huh, "Recent studies in turbine blade internal cooling", Heat Transfer Research, 41, 803$828,2010$.

[4] Luca Andrei, Antonio Andreini, Bruno Facchini, Lorenzo Winchler, "A decoupled CHT procedure: application and validation on a gas turbine vane with different cooling configurations", Energy Procedia, 45, 1087 - 1096, 2014.

[5] B. Sunden, G. Xie, "Gas turbine blade tip heat transfer and cooling: a literature survey", Heat Transfer Engingeering, 31, 527-554, 2010.

[6] Emad Elnajjar, Mohammad O. Hamdan, Yousef Haik, "Experimental Investigation of Internal Channel Cooling Via Jet Impingement", FDMP, 9, 1, 77-89, 2013.

[7] Ebru Öztekin, Orhan Aydin, Mete Avc1. "Hydrodynamics of a turbulent slot jet flow impinging on a concave surface." International Communications in Heat and Mass Transfer, 39.10, 1631-1638, 2012.

[8] Ebru Öztekin, Orhan Aydin, Mete Avc1. "Heat transfer in a turbulent slot jet flow impinging on concave 
surfaces. International Communications in Heat and Mass Transfer. 44, 77-82, 2013.

[9] M. O. Hamdan, E. Elnajjar, Y.Haik, "Measurement and Modeling of Confined Jet Discharged Tangentially on a Concave Semi cylindrical Hot Surface" Journal of Heat Transfer, 133, 12, 122203-09, December 2011.

[10] Yang, Yue-Tzu, Tzu-Chieh Wei, and Yi-Hsien Wang. "Numerical study of turbulent slot jet impingement cooling on a semicircular oncave surface." International Journal of Heat and Mass Transfer 54.1 (2011): 482-489.

[11] M.K. Isman, E. Pulat, A.B. Etemoglu, M. Can, "Numerical investigation of turbulent impinging jet cooling of a constant heat flux surface", Numerical Heat Transfer, Part A, 53, 1109-1132, "2008.

[12] Dieter E. Bohn, Volker J. Becker and Agnes U. Rungen, Experimental And Numerical Conjugate Flow And Heat Transfer Investigation of A Shower-Head Cooled Turbine Guide Vane", Proceedings of the International Gas Turbine \& Aero engine Congress \& Exhibition, Orlando, Florida, 1-12, June 2-5, 1997.

[13] Grzegorz Nowak, Włodzimierz Wroblewski, "Cooling system optimisation of turbine guide vane", Applied Thermal Engineering, 29, 567-572, 2009.

[14] Zhao Liu, Jun Li, Zhenping Feng, Terrence Simon, "Numerical study on the effect of jet nozzle aspect ratio and jet angle on swirl cooling in a model of a turbine blade leading edge cooling passage", International Journal of Heat and Mass Transfer, 90, 986-1000, 2015.

[15] Wei Jia, Huoxing Liu, "Numerical investigation of the effect of rim seal on turbine aerodynamic design parameters and end wall flows in low-aspect ratio turbine", Computers \& Fluids, 74,114-125, 2013.

[16] R. Saravanan, R. Pugazhenthi, P. Vivek and M. Santhanam, "Design and Simulation of a TwoWheeled Inverted Pendulum - a Balanced, Easy Moving Vehicle for the Material Handling", American-Eurasian Journal of Scientific Research 11 (3): 189-198, 2016.

[17] R Saravanan, P Vivek, T Vinod Kumar, "Is Kevlar29/Epoxy Composite an Alternate for Drive Shaft?", Journal of Advances in Mechanical Engineering and Science, 2(3), 1-13, 2016.

[18] M. Zielińska, J. Sieniawski, "Surface Modification and its Influence on the Microstructure and Creep Resistance of Nickel based Superalloy Rene 77", Archives of Metallurgy And Materials, 58, 1, 95-98. 2013. 